\title{
Rates of post-traumatic stress disorder in trauma-exposed children and adolescents: meta-analysis
}

Eva Alisic, Alyson K. Zalta, Floryt van Wesel, Sadie E. Larsen, Gertrud S. Hafstad, Katayun Hassanpour and Geert E. Smid

\section{Background}

It is unclear how many children and adolescents develop post-traumatic stress disorder (PTSD) after trauma.

\begin{abstract}
Aims
To determine the incidence of PTSD in trauma-exposed children and adolescents as assessed with well-established diagnostic interviews and to examine potential moderators of the estimate.

\section{Method}

A systematic literature search identified 72 peer-reviewed articles on 43 independent samples $(n=3563)$. Samples consisting only of participants seeking or receiving mental health treatment were excluded. Main analyses involved pooled incidence estimates and meta-analyses of variance.
\end{abstract}

\section{Results}

The overall rate of PTSD was 15.9\% (95\% Cl 11.5-21.5), which varied according to the type of trauma and gender. Least at risk were boys exposed to non-interpersonal trauma (8.4\%, 95\% Cl 4.7-14.5), whereas girls exposed to interpersonal trauma showed the highest rate $(32.9 \%, 95 \% \mathrm{Cl} 19.8-49.3)$. No significant difference was found for the choice of assessment interview or the informant of the assessment.

\section{Conclusions}

Research conducted with the best available assessment instruments shows that a significant minority of children and adolescents develop PTSD after trauma exposure, with those exposed to interpersonal trauma and girls at particular risk. The estimates provide a benchmark for DSM-5 and ICD-11.

\section{Declaration of interest}

None.
It is unclear how many children and adolescents develop post-traumatic stress disorder (PTSD) after exposure to trauma. In a summary of the literature, one investigator noted that rates ranged from $0 \%$ to $100 \% .{ }^{1}$ A meta-analysis conducted in 1994 estimated that $36 \%$ of children exposed to trauma went on to develop PTSD; ${ }^{2}$ however, the inclusion criteria and analytic strategy of this meta-analysis are unknown, and many new studies have since been conducted. The wide variability in estimates suggests that moderators have a role. For example, interpersonal trauma (e.g. assault, war) is thought to result in higher rates of PTSD than non-interpersonal trauma (e.g. accident, natural disaster). ${ }^{3,4}$ Evidence also suggests that girls are more likely to develop PTSD than boys, ${ }^{4,5}$ although this may be related to differences in type of exposure. ${ }^{6}$ Furthermore, studies show that parentchild agreement regarding PTSD symptoms is relatively poor, ${ }^{7,8}$ indicating a need to assess differences across informants. Finally, the specific instrument used to assess PTSD may have a role. We aimed first to establish an estimate of the risk of DSM-IV PTSD among children and adolescents exposed to trauma, based on well-established diagnostic interviews; second, to examine potential moderators (i.e. type of trauma, gender, informant and diagnostic measure) that could affect this estimate; and finally, if group differences were found, to report separate estimates of PTSD rates. A precise estimate of the proportion of children developing PTSD after traumatic exposure would allow for a better appraisal of the need for mental health resources, better allocation of these resources to those most in need and a better design of new studies in youth (e.g. with respect to power of the analyses). It would also provide a benchmark for evaluating the impact of the new DSM-5 criteria on rates of PTSD among traumatised children and adolescents.

\section{Method}

To obtain the most accurate PTSD rates we targeted studies that applied widely used and well-established diagnostic interviews for childhood PTSD according to DSM-IV criteria. Based on three reviews of PTSD measures for children and adolescents, ${ }^{5,10,11}$ we included the Clinician Administered PTSD Scale for Children and Adolescents (CAPS-CA), the Anxiety Disorders Interview Schedule for DSM-IV - Child version (ADIS-C), the Diagnostic Interview for Children and Adolescents - Revised (DICA-R), the Schedule for Affective Disorders and Schizophrenia for SchoolAge Children - Present and Lifetime version (K-SADS) and the Children's PTSD Inventory (CPTSDI). ${ }^{12-16}$

Relevant studies were identified through systematic searches in four electronic databases - PubMed, EMBASE, PsycINFO and the Published International Literature on Traumatic Stress (PILOTS) - and reference lists of systematic reviews on child trauma., ${ }^{2,17-22}$ Electronic searches included the following keywords, with syntax adapted to the specified databases: "Clinician-Administered" OR "CAPS-CA" OR “CAPS-C" OR "CAPS" OR “KSADS” OR ("Kiddie Schedule") OR "K-SADS" OR "KSADS" OR ("Kiddie SADS") OR "ADIS-C" OR "ADISC" OR ("Anxiety and Depression Interview Schedule") OR ("Diagnostic Interview for Children") OR "DICA" OR "DICA-R" OR "DICAR" OR "CPTSDI" OR ("PTSDI" AND Saigh) OR ("PTSD Inventory")] AND ["PTSD" OR ("Post-traumatic stress disorder") OR ("Posttraumatic stress disorder")] AND [child OR children OR adolescents OR adolescent OR youth OR youths OR youngster OR youngsters OR toddler OR toddlers OR infant OR infants OR kid OR kids OR teen OR teens OR teenager OR teenagers OR preschooler OR preschoolers]. We restricted searches to empirical Englishlanguage papers with at least 10 participants (to avoid selection 
bias in case series), published in peer-reviewed journals between 1994 (when DSM-IV was published) and 1 October 2012. In addition the studies had to satisfy the following criteria:

(a) the study participants were all exposed to trauma as defined by the Al criterion for PTSD in DSM-IV, or separate data for this group were available;

(b) the study participants were less than 19 years old at the time of the PTSD measurement;

(c) the study participants did not represent a clinical sample with respect to mental health (e.g. psychiatric in-patients or a sample of children with post-traumatic stress symptoms seeking mental healthcare);

(d) the study protocol did not include a psychological or psychopharmacological intervention (i.e. potentially attracting participants with higher levels of distress);

(e) the study examined PTSD diagnosis at least 1 month after the trauma, according to DSM-IV criteria, with one of the five specified interviews or one of their revisions;

(f) the study did not have the psychometric evaluation of the diagnostic interview as its sole purpose;

(g) the article and/or the study author(s) provided enough information to derive the percentage of children who satisfied the criteria for PTSD diagnosis.

Screening and selection of studies (see Fig. 1) were conducted by E.A. and a trained research assistant, with differences and questions being resolved through consultation with at least one other member of the research team. We obtained full-text articles for all studies that were potentially relevant. In the few situations where eligibility remained unclear based on the article, we contacted the study authors for additional information.

\section{Coding of studies}

Each study was coded based on consensus by at least three members of the research team. In addition to the publication details of each study, we extracted information on the sample, the nature of trauma exposure, the measurement of PTSD and the outcomes of the PTSD assessment (the coding manual is available from E.A.). Study authors were contacted to confirm codes and provide any coding information that was not included in the articles.

\section{Sample characteristics}

We recorded country of data collection, the number of children and adolescents who participated in the PTSD assessment, age of the sample (range, mean, standard deviation), the percentage of boys and any exclusion criteria that the authors applied.

\section{Exposure characteristics}

We noted a short description of the event and the type of exposure. The pre-specified types were disaster, war, terrorism, (injury due to) accident, (injury due to) violence, life-threatening disease, sudden death of a loved one, 'mixed' with violence, 'mixed' without violence. This variable was used to derive two categories: interpersonal trauma - war, terrorism, (injury due to) violence and 'mixed' with violence - and non-interpersonal trauma - disaster, (injury due to) accident, life-threatening disease, sudden death of a loved one and 'mixed' without violence.

\section{PTSD measurement}

We documented the number of times that PTSD was measured, the timing of these measurements (mean number of months post-trauma and range), the informant (child, parent, combination or other) and the clinical interview used.

\section{Outcomes of the assessment}

We recorded the number of children and adolescents with full PTSD according to DSM-IV and how many of them were boys. In cases of multiple measurements within one study, we recorded the information on the first eligible wave (i.e. at least 1 month post-trauma).

\section{Statistical analysis}

The analyses were performed using Comprehensive Meta-Analysis, SPSS version 19.0 for Windows Vista and the macros provided by Wilson. ${ }^{23}$ We used random effects models to compute all pooled estimates based on the assumption that true effect sizes are likely to vary beyond subject-level sampling error. ${ }^{24}$ The first stage of our data analysis involved determining an overall pooled incidence estimate of PSTD in children and adolescents who were exposed to a traumatic event, based on all included studies. Estimates of the proportion of traumatised youth with PTSD were transformed into logits for better estimation prior to the calculations and transformed back to proportions afterwards for ease of interpretation (Lipsey \& Wilson: pp. 39-40). ${ }^{24}$ When outcomes in individual studies equalled $0 \%$, we added 0.5 to both cells (containing frequencies of events and non-events) before applying the logit transformation. To scan for possible outliers, we made a box plot. All observations more extreme than 1.5 times the interquartile range were marked as outliers. Following outlier detection we performed a sensitivity analysis to investigate the influence of the outliers. Next, tests of heterogeneity (Cochran's Q) were performed to determine whether differences in estimates across studies were greater than expected by chance. We also evaluated possible publication bias by inspection of a funnel plot. Because the Q-test was significant we subsequently evaluated the sources of variability in the pooled incidence estimate. We performed meta-analyses of variance (ANOVAs) for all moderators of interest (type of trauma, gender, choice of interview, informant), calculating pooled estimates for all group levels. To test for significant differences in pooled incidence estimates between groups we used a Q-between test (Lipsey \& Wilson: p. 136). ${ }^{24}$ Whereas type of trauma, choice of interview and informant were between-sample moderators, gender was a within-sample moderator. Therefore, we created separate boys and girls 'samples' based on the numbers of boys and girls in each sample and the number of PTSD diagnoses for them.

\section{Results}

We retrieved 72 articles describing 43 independent samples, denoted as $k$ (Fig. 1). In total they reported PTSD assessments for 3563 children and adolescents exposed to trauma as defined by criterion A1 of DSM-IV. All samples also met the DSM-5 exposure criterion. An overview of the samples and their references are given in online Table DS1. Child ages varied from 2 years to 18 years and approximately $57 \%$ of the children were boys (not reported for two samples). Most samples originated in the USA $(k=20 ; 47 \%)$, followed by the UK and Australia (both $k=5 ; 12 \%)$. Three samples came from non-Western countries (Afghanistan, China and South Africa). The children had been exposed to a variety of events, including motor vehicle accidents, the sudden loss of a parent, life-threatening illness, war experiences, domestic violence and child maltreatment. About half of the samples $(k=22 ; 51 \%)$ had been exposed to non-interpersonal 


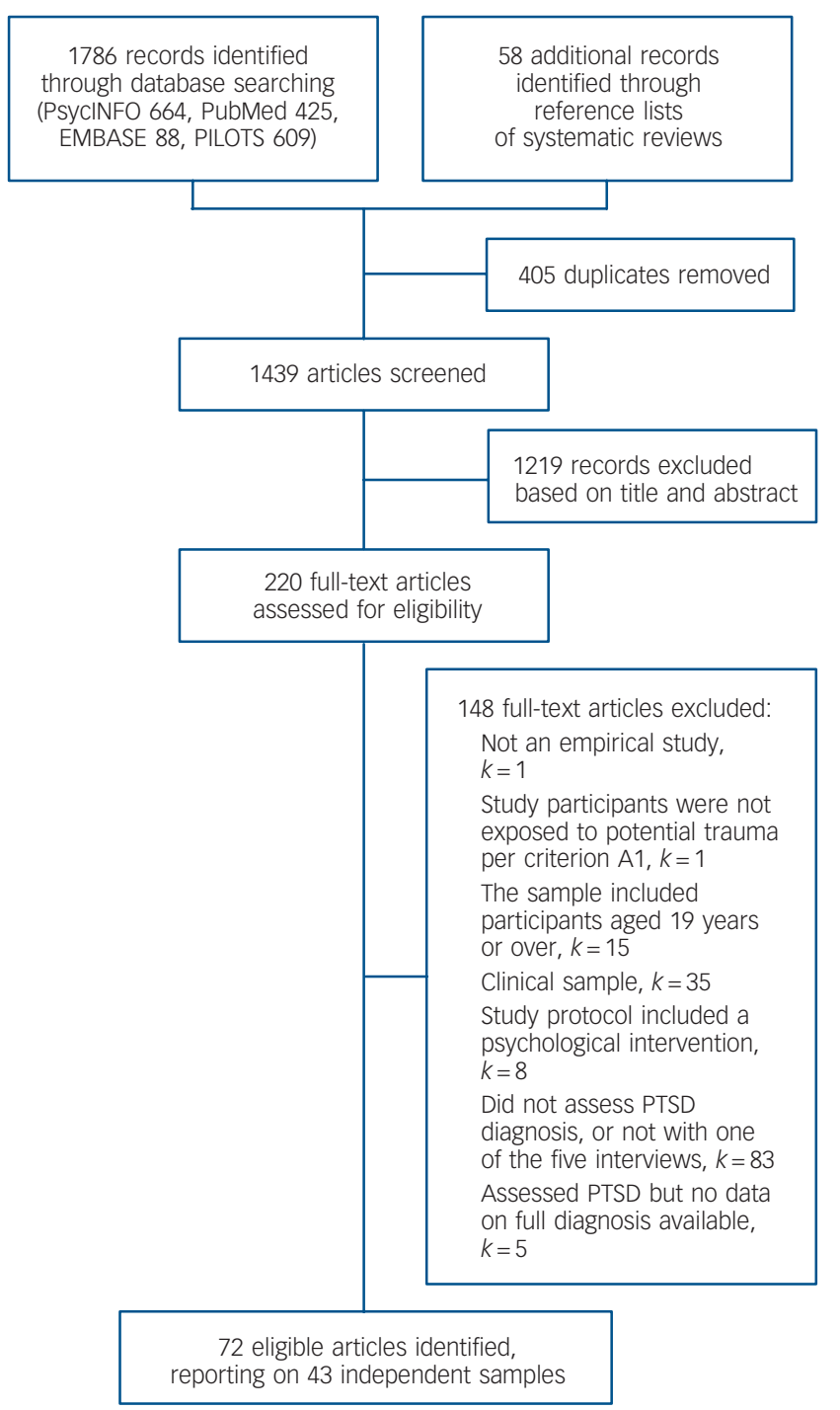

Fig. 1 Selection of samples (PTSD, post-traumatic stress disorder).

trauma and the other half $(k=21 ; 49 \%)$ to interpersonal trauma or to a mix of both. The studies applied a range of exclusion criteria. Frequently excluded were participants with cognitive impairments $(k=25 ; 58 \%)$, insufficient language skills $(k=13$; $30 \%)$, prior trauma $(k=9 ; 21 \%)$ and current or prior mental health problems $(k=9 ; 21 \%)$. The most commonly used instrument to assess PTSD was the CAPS-CA $(k=19 ; 44 \%)$ and the least used was the CPTSDI $(k=4 ; 9 \%)$. In the majority of the samples $(k=31 ; 72 \%)$ the children were the informants as opposed to the parents $(k=4 ; 9 \%)$. In 8 samples $(19 \%)$ a combined reporting strategy was used. Reported rates of PTSD ranged from $0 \%$ to $89 \%$.

\section{Outlier analysis, sensitivity analyses and publication bias}

One study was detected as an outlier on the box plot. ${ }^{25}$ This study included a sample of youths highly exposed to interpersonal trauma. Sensitivity analysis revealed that without this study the pooled incidence estimate dropped from $16.9 \%$ (95\% CI $12.1-23.2$ ) to $15.9 \%$ (95\% CI 11.5-21.5\%). We performed the remainder of the analyses without this observation. We assessed possible publication bias (i.e. the preferential publication of striking findings, in this case high PTSD rates) by inspection of a funnel plot. Although the plot was asymmetrical, this asymmetry was not consistent with publication bias, as smaller studies tended to yield lower estimates of PTSD. Additional sensitivity analyses included assessment of the influence of each study on the overall estimates of PTSD rates by recalculating the pooled outcome proportions with one study removed and all others included. These analyses yielded PTSD estimates ranging from 15.1\% (95\% CI $11.0-20.5$ ) to $16.6 \%$ (95\% CI $12.1-22.4$ ).

\section{Pooled incidence estimate}

For the overall sample $(k=42)$ we found that $15.9 \%$ (95\% CI 11.5-21.5) of the children and adolescents exposed to a traumatic event developed PTSD (Fig. 2). The Q-test for pooled estimates

\begin{tabular}{|c|c|c|c|c|c|}
\hline Study & TSD Ré & $e$ and & $5 \% \mathrm{Cl}$ & & \\
\hline & $\%$ & & & & \\
\hline $\begin{array}{l}\text { Ahmad et al }(2000)^{44} \\
\text { Bal et al }(2004)^{45}\end{array}$ & 9.1 & $\begin{array}{r}4.1 \\
403\end{array}$ & $\begin{array}{l}18.8 \\
597\end{array}$ & - & \\
\hline Bayarri Fernandez & & & & & \\
\hline $\begin{array}{l}\text { et al }(2011)^{46} \\
\text { Bosquet Enlow et al }\end{array}$ & 6.3 & 3.3 & 11.6 & 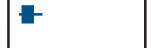 & \\
\hline$(2010)^{47}$ & 17.0 & 10.8 & 25.7 & & \\
\hline $\begin{array}{l}\text { Bui et al }(2010)^{48,4} \\
\text { Catani et al (2009) }\end{array}$ & 4.9 & 2.1 & 11.2 & & \\
\hline $\begin{array}{l}\text { Catani et al (2009) }{ }^{50} \\
\text { Chemtob \& Carlson }\end{array}$ & 48.1 & 30.4 & 66.4 & & \\
\hline$(2004)^{51}$ & 41.7 & 24.1 & 61.7 & & \\
\hline Daud et al $(2005)^{52,53}$ & 48.9 & 34.8 & 63.2 & & \\
\hline $\begin{array}{l}\text { Daviss et al }(2000)^{54} \\
\text { Delahanty et al }\end{array}$ & 12.5 & 5.7 & 25.2 & & \\
\hline$(2005)^{55-58}$ & 6.6 & 2.8 & 14.9 & & \\
\hline Erickson et al (2008) & 13.8 & 5.3 & 31.5 & & \\
\hline Iselin et al $(2010)^{60,61}$ & 4.3 & 2.2 & 8.5 & a & \\
\hline $\begin{array}{l}\text { Ji et al }(2010)^{62} \\
\text { Jones-Alexander }\end{array}$ & 5.3 & 3.4 & 8.2 & a & \\
\hline $\begin{array}{l}\text { et al }(2005)^{63} \\
\text { Kenardy et al (2006) }\end{array}$ & 23.8 & 10.3 & 46.0 & & \\
\hline $\begin{array}{l}\text { (partly } \\
\text { Kenardy et al (2006) }\end{array}$ & 0.7 & 0.1 & 4.9 & F & \\
\hline (partly) & 2.2 & 0.6 & 8.5 & 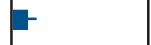 & \\
\hline $\begin{array}{l}\text { Kolko }(1998)^{69,70} \\
\text { Landolt et al }(1998)^{71}\end{array}$ & $\begin{array}{l}23.3 \\
5.2\end{array}$ & $\begin{array}{l}15.7 \\
325\end{array}$ & $\begin{array}{l}33.2 \\
71.2\end{array}$ & & \\
\hline Landolt et al $(2009)^{72}$ & 18.6 & 9.6 & 33.0 & & \\
\hline $\begin{array}{l}\text { Lemos-Miller } \\
\text { \& Kearney }(2006)^{37}\end{array}$ & 35.6 & 26.4 & 45.9 & & \\
\hline $\begin{array}{l}\text { Linning \& Kearney } \\
(2004)^{13}\end{array}$ & 67.3 & 53.9 & 78.3 & & $\rightarrow-$ \\
\hline $\begin{array}{l}\text { MacMillan et al } \\
(2009)^{74,75}\end{array}$ & 26.2 & 16.9 & 38.1 & & \\
\hline Mather et al (2003) & 41.9 & 28.2 & 56.9 & & \\
\hline Max et al $(2011)^{77}$ & 2.8 & 1.1 & 7.3 & t & \\
\hline $\begin{array}{l}\text { Meiser-Stedman } \\
\text { et al }(2005)^{78-82}\end{array}$ & 12.5 & 6.4 & 23.1 & & \\
\hline $\begin{array}{l}\text { Meiser-Stedman } \\
\text { et al (2008a) }\end{array}$ & 1.7 & 0.2 & 10.9 & & \\
\hline $\begin{array}{l}\text { Meiser-Stedman } \\
\text { et al (2008b) }\end{array}$ & 18.8 & 10.1 & 32.3 & & \\
\hline $\begin{array}{l}\text { Melhem et al } \\
(2007)^{83-85}\end{array}$ & 8.8 & 5.5 & 13.9 & & \\
\hline Nixon et al (2010) ${ }^{86}$ & 4.7 & 1.8 & 11.7 & E- & \\
\hline $\begin{array}{l}\text { Ostrowskl et al } \\
(2007)^{87,88}\end{array}$ & 2.0 & 0.3 & 12.9 & - & \\
\hline Ostrowski et al (2011) & 0.5 & 0.0 & 7.5 & 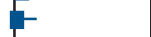 & \\
\hline Pervanidou et al $(2007)^{90-92}$ & 240.4 & 28.5 & 53.5 & $\rightarrow$ & \\
\hline Pfeffer et al $(2007)^{93}$ & 28.9 & 17.6 & 43.6 & & \\
\hline Pine et al $(2005)^{94-96}$ & 55.2 & 46.1 & 64.0 & & - \\
\hline Rees et al (2004)97 & 5.3 & 0.7 & 29.4 & & \\
\hline Rosner et al (2012) ${ }^{36}$ & 12.5 & 4.8 & 28.9 & & \\
\hline Samuelson et al $(2010)^{98}$ & 29.0 & 19.1 & 41.4 & -1 & \\
\hline Schäfer et al (2006) & 0.7 & 0.0 & 10.4 & & \\
\hline Stallard et al $(1998)^{100,101}$ & 35.3 & 27.2 & 44.4 & & \\
\hline Suliman et al $(2005)^{38}$ & 22.0 & 12.6 & 35.5 & -1 & \\
\hline $\begin{array}{l}\text { Vanderbilt et al }(2008)^{102} \\
\text { Winston et al }(2003)^{103-106}\end{array}$ & $\begin{array}{r}35.3 \\
5.4\end{array}$ & $\begin{array}{r}16.8 \\
3.0\end{array}$ & $\begin{array}{r}59.6 \\
9.5\end{array}$ & & \\
\hline Overall/Pooled & 15.9 & 11.5 & 21.5 & & \\
\hline & & & & & \\
\hline
\end{tabular}

Fig 2 Forest plot of post-traumatic stress disorder (PTSD) rates in individual samples (for full references, see online data supplement). 
was significant $(Q=495.5$, d.f. $=41 ; P<0.001)$, indicating heterogeneity between studies. We therefore proceeded to conduct moderator analyses.

\section{Moderator analyses}

We conducted meta-ANOVAs to test differences in the pooled incidence estimate based on type of trauma, gender, choice of diagnostic interview and informant of the assessment (Table 1). The PTSD rate following non-interpersonal trauma was 9.7\% (95\% CI 6.1-15.2), whereas following interpersonal trauma it was $25.2 \% \quad(95 \%$ CI $16.8-35.8)$, a significant difference $(P=0.002)$. Boys developed significantly less PTSD (11.1\%, 95\% CI 7.0-17.1) than girls $(20.8 \%, 95 \%$ CI $13.6-30.5 ; P=0.04)$. Table 1 also shows the PTSD rates for type of trauma by gender. Boys exposed to non-interpersonal trauma showed the lowest rates of PTSD $(8.4 \%, 95 \%$ CI $4.7-14.5)$ whereas girls exposed to interpersonal trauma showed the highest rates $(32.9 \%$, 95\% CI 19.8-49.3); see Fig. 3 for forest plots of the subgroups. There was no significant difference in PTSD rates related to the informant or to the diagnostic interview used for the assessment.

\section{Discussion}

There has been substantial uncertainty regarding the incidence of PTSD in children and adolescents exposed to trauma. Our metaanalysis summarises the evidence collected with well-established diagnostic interviews. Our findings indicate that, overall, approximately one in six children and adolescents (16\%) developed PTSD after exposure to a DSM-IV criterion A1 or DSM-5 trauma. There was considerable variation in this rate based on the type of trauma: approximately one in ten developed PTSD after non-interpersonal trauma, whereas one in four developed PTSD after interpersonal trauma. Variation was also related to gender, with girls being at higher risk than boys. The overall rate of $16 \%$ is lower than the estimate of $36 \%$ reported in a previous review. ${ }^{2}$ However, given that the book chapter reporting the estimate did not describe the method used, it is difficult to compare the two findings. The sizeable difference may be related to assessment methods: whereas we focused on diagnoses made through clinical interviews, it appears that the previous review also included rates based on scores above cut-off on self-report questionnaires. The latter have been shown to overestimate PTSD in adults. ${ }^{9}$ Nevertheless, $16 \%$ represents a significant minority of children and indicates that the full burden of trauma, including other mental health consequences such as generalised anxiety disorder, depression and separation anxiety disorder, ${ }^{26}$ is substantial.

Consistent with findings in the adult literature, ${ }^{27,28}$ the most prominent moderator of PTSD rates was the type of trauma. Interpersonal trauma may lead to higher rates of PTSD because it is more often chronic, erodes social support (in cases where the perpetrator is a family member), leads to more self-blame or other maladaptive cognitions, ${ }^{6}$ represents a 'betrayal' of trust, ${ }^{29}$ or more clearly 'shatters assumptions' about the world in ways that affect daily functioning. ${ }^{30}$ Our findings suggest that screening and treatment resources will in particular need to be allocated to children exposed to interpersonal trauma. In addition, the time lag between exposure and assessment (without structured psychological care in between) was often large for these samples, underlining a need for early detection of both exposure and mental health problems. Especially in childhood and adolescence, when the risk of a cascade of disruptions in development is high, ${ }^{4,31-33}$ timely intervention is essential. Girls were more likely than boys to develop PTSD following trauma exposure. This might be partially due to their greater exposure to interpersonal trauma. ${ }^{27}$ However, researchers have generally noted that although differences in rates of interpersonal trauma contribute to different rates of PTSD, they do not fully explain the trend. ${ }^{6}$ This finding is consistent with our observations. Future research should explore

\begin{tabular}{|c|c|c|c|c|c|}
\hline \multirow[b]{2}{*}{ Predictor } & \multirow{2}{*}{$\begin{array}{c}\text { Rate } \\
\%(95 \% \mathrm{Cl})\end{array}$} & \multirow[b]{2}{*}{$k^{\mathrm{a}}$} & \multicolumn{3}{|c|}{ Between-group homogeneity } \\
\hline & & & $Q$ & d.f. & $P$ \\
\hline \multicolumn{6}{|l|}{ Type of trauma } \\
\hline Non-interpersonal & $9.7(6.1-15.2)$ & 22 & 9.66 & 1 & 0.002 \\
\hline Interpersonal & $25.2(16.8-35.8)$ & 20 & & & \\
\hline \multicolumn{6}{|l|}{ Gender } \\
\hline Boys & $11.1(7.0-17.1)$ & 30 & 4.11 & 1 & 0.043 \\
\hline Girls & $20.8(13.6-30.5)$ & 31 & & & \\
\hline \multicolumn{6}{|l|}{ Type of trauma by gender ${ }^{\mathrm{b}}$} \\
\hline Boys - non-interpersonal & $8.4(4.7-14.5)$ & 18 & 13.03 & 3 & 0.005 \\
\hline Boys - interpersonal & $16.8(8.8-29.6)$ & 12 & & & \\
\hline Girls - non-interpersonal & $13.3(7.4-22.9)$ & 18 & & & \\
\hline Girls - interpersonal & $32.9(19.8-49.3)$ & 13 & & & \\
\hline \multicolumn{6}{|l|}{ Choice of diagnostic interview } \\
\hline ADIS-C & $9.8(4.1-21.4)$ & 8 & 8.17 & 4 & 0.086 \\
\hline CAPS-CA & $12.1(7.2-19.7)$ & 18 & & & \\
\hline DICA-R & $19.0(7.6-40.0)$ & 5 & & & \\
\hline K-SADS & $22.6(11.4-39.8)$ & 8 & & & \\
\hline CPTSDI & $51.4(17.4-84.1)$ & 2 & & & \\
\hline \multicolumn{6}{|l|}{ Informant } \\
\hline Child & $17.3(11.8-24.7)$ & 30 & 3.53 & 2 & 0.171 \\
\hline Parent & $5.1(1.3-17.4)$ & 4 & & & \\
\hline Combined & $13.4(5.7-28.4)$ & 7 & & & \\
\hline \multicolumn{6}{|c|}{$\begin{array}{l}\text { ADIS-C, Anxiety Disorders Interview Schedule for DSM-IV - Child version; CAPS-CA, Clinician Administered PTSD Scale for Children and Adolescents; CPTSDI, Children's PTSD } \\
\text { Inventory; DICA-R, Diagnostic Interview for Children and Adolescents - Revised; K-SADS, Schedule for Affective Disorders and Schizophrenia for School-Age Children - Present and } \\
\text { Lifetime version. } \\
\text { a. Number of samples. } \\
\text { b. POst hoc analyses involving the samples for which we had separate information on boys and girls }(k=31) \text { showed a significant difference between non-interpersonal and } \\
\text { interpersonal trauma in the girls' samples }(Q=5.31 \text {, d.f. }=1, P=0.021) \text { and a trend in the boys' samples }(Q=2.77, \text { d.f. }=1, P=0.096) \text {. There was no significant difference between } \\
\text { boys and girls for the non-interpersonal trauma samples }(Q=1.23, \text { d.f. }=1, P=0.268) \text { and a trend for the interpersonal trauma samples }(Q=3.06 \text {, d.f. }=1, P=0.080) \text {. }\end{array}$} \\
\hline
\end{tabular}


Type of trauma

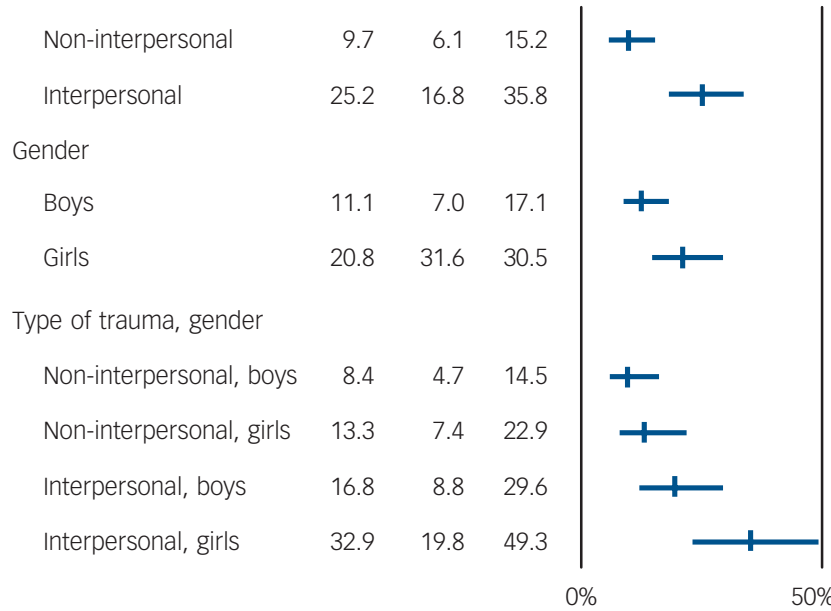

Fig 3 Forest plot of subgroups (PTSD, post-traumatic stress disorder).

explanations for these differences. These explanations might include boys' higher likelihood of engaging in externalising rather than internalising behaviours following trauma; ${ }^{6}$ girls' higher rates of internalising disorders in general (both before and after trauma) $;^{34}$ girls' stronger self-blaming or threat appraisal; ${ }^{6}$ girls' experience of peritraumatic dissociation or girls' increased hypothalamic-pituitary-adrenal (HPA) axis dysregulation. ${ }^{27}$ When more studies in different age ranges are available it will be interesting to test whether gender differences arise around pre-adolescence, given that gender differences in other internalising disorders tend to surface around this time. ${ }^{34}$

\section{Study limitations}

The limitations of our study need to be considered. First, because of our decision to include only studies applying well-established interviews, children traumatised by war or disaster were underrepresented. Our findings will need to be compared with the best available assessments in these samples in the future. Second, although we have used the term 'incidence' for the proportion of children who developed PTSD after a traumatic event, it could be argued that we have measured point prevalence in a specific group; ${ }^{35}$ most primary studies were cross-sectional in nature and did not assess whether children had recovered from PTSD between exposure and assessment. Third, it was not possible to examine time since trauma as a potential moderator. Many studies, in particular those after interpersonal trauma, reported a wide variability in the timing of the assessments, ${ }^{36-38}$ and using the sample mean in this case would be vulnerable to aggregation bias. ${ }^{39}$ Visual inspection of the few studies with multiple time points indicated a slight decrease of PTSD rates over time. Fourth, although we applied quite strict inclusion and exclusion criteria, some potential forms of bias or confounding (e.g. with the chronic nature of certain types of trauma and the way they are detected) could not be ruled out and will need to be taken into account in the future. In particular, more than half of the samples excluded participants with cognitive limitations and about one in four samples excluded children and adolescents with a current or prior mental health diagnosis (ranging from depression to psychosis), medication or trauma history. Given the known vulnerability of these children, ${ }^{40,41}$ the included studies may have underestimated the true PTSD incidence rates following exposure.

\section{Implications}

With the release of DSM-5 and the imminent release of ICD-11, this study may serve as a benchmark for forthcoming research on childhood PTSD. At least one study has found that, compared with DSM-IV, the DSM-5 criteria may lead to similar or slightly lower PTSD rates in adults, ${ }^{42}$ but we have yet to determine what this will mean for child populations. In particular, earlier criticisms of the diagnosis related to its lack of child-centredness, ${ }^{43}$ and led to the inclusion of the new subtype 'pre-school PTSD', which may yield larger detection rates. For example, Meiser-Stedman et al reported an almost six-fold increase (from 1.7\% according to DSM-IV to $10.0 \%$ according to an algorithm similar to 'pre-school PTSD') for a sample of children 2-6 years old exposed to motor vehicle accidents. ${ }^{7}$ The ICD has been seen as more childfriendly but has served less often as a basis for child assessment in studies (hence our focus on DSM). It will be important for future research to determine whether the DSM-5 and the ICD-11 criteria align well with children's functional outcomes. Until then, our findings provide critical information regarding expected rates of PTSD among trauma-exposed children and adolescents.

Eva Alisic, PhD, Monash Injury Research Institute, Monash University, Monash, Australia, and University Medical Centre, Utrecht, The Netherlands; Alyson K. Zalta $\mathrm{PhD}$, Departments of Psychiatry and Behavioral Sciences, Rush University Medical Center, Chicago, Illinois, USA; Floryt van Wesel, PhD, Department of Educational Center, Chicago, Illinois, USA; Floryt van Wesel, PhD, Department of Educational
Neuroscience, VU University, Amsterdam, The Netherlands; Sadie E. Larsen, PhD, Clement J. Zablocki VA Medical Center, Department of Psychiatry, Medical College of Wisconsin, Milwaukee, Wisconsin, USA; Gertrud S. Hafstad, PhD, Norwegian Centre for Violence and Traumatic Stress Studies, Oslo, Norway; Katayun Hassanpour, MD, Department of Psychiatry and Psychotherapy, University Hospital, Zürich, Switzerland: Geert E. Smid, MD, PhD, Foundation Centrum '45, Arq Research Program, Diemen, The Netherlands

Correspondence: Dr Eva Alisic, Monash Injury Research Institute, Building 70, Monash University, VIC 3800, Australia. Email: eva.alisic@monash.edu

First received 23 Apr 2013, final revision 21 Oct 2013, accepted 3 Dec 2013

\section{Acknowledgements}

We thank Marit van den Heuvel and Marjolein Pottinga for their assistance in the screening and selection of eligible studies. We thank Drs Bosquet Enlow, Bui, Catani, Daud, Daviss, Dowe, Erickson, Jones-Alexander, Kassam-Adams, Kaufman, Kenardy, Kearney, Kolaitis, Landolt, Le Brocque, MacMillan, Masten, Max, Meiser-Stedman, Melhem, Nixon, Nugent, Ostrowski, Pine, Rosner, Rydelius, Samuelson, Schäfer, Suliman, Vanderbilt and colleagues for providing information about their studies. This meta-analysis is a project grown out of the Paper in a Day session of the 2012 annual meeting of the International Society for Traumatic Stress Studies.

\section{References}

1 Yule W. Posttraumatic stress disorder in the general population and in children. J Clin Psychiatry 2001; 17: 23-8.

2 Fletcher KE. Childhood posttraumatic stress disorder. In Child Psychopathology (eds EJ Mash, RA Barkley): 330-71. Guilford, 2003.

3 Copeland WE, Keeler G, Angold A, Costello EJ. Traumatic events and posttraumatic stress in childhood. Arch Gen Psychiatry 2007; 64: 577-84.

4 Nooner KB, Linares LO, Batinjane J, Kramer RA, Silva R, Cloitre M. Factors related to posttraumatic stress disorder in adolescence. Trauma Violence Abuse 2012; 13: 153-66.

5 Dyregrov A, Yule W. A review of PTSD in children. Child Adolesc Ment Health 2006; 11: 176-84.

6 Tolin DF, Foa EB. Sex differences in trauma and posttraumatic stress disorder: a quantitative review of 25 years of research. Psychol Bull 2006; 132: 959-92.

7 Meiser-Stedman R, Smith P, Glucksman E, Yule W, Dalgleish T. The posttraumatic stress disorder diagnosis in preschool- and elementary 
school-age children exposed to motor vehicle accidents. Am J Psychiatry 2008; 165: 1326-37.

8 Dyb G, Holen A, Braenne K, Indredavik MS, Aarseth J. Parent-child discrepancy in reporting children's post-traumatic stress reactions after a traffic accident. Nord J Psychiatry 2003; 57: 339-44.

9 Richardson LK, Frueh BC, Acierno R. Prevalence estimates of combat-related post-traumatic stress disorder: critical review. Aust NZ J Psychiatry 2010; 44 4-19.

10 Ohan JL, Myers K, Collett BR. Ten-year review of rating scales. IV: Scales assessing trauma and its effects. J Am Acad Child Adolesc Psychiatry 2002; 41: 1401-22.

11 Hawkins SS, Radcliffe J. Current measures of PTSD for children and adolescents. J Pediatr Psychol 2006; 31: 420-30.

12 Nader K, Kriegler JA, Blake DD, Pynoos RS, Newman E, Weather FW. Clinician Administered PTSD Scale, Child and Adolescent Version. National Center for PTSD, 1996

13 Silverman WK, Albano AM. ADIS: Anxiety Disorders Interview Schedule for DSM-IV: Child version. Psychological Corporation, 1996.

14 Reich W, Leacock N, Shanfield C. Diagnostic Interview for Children and Adolescents - Revised (DICA-R). Washington University, 1994.

15 Kaufman J, Birmaher B, Brent D, Rao U, Flynn C, Moreci P, et al. Schedule for Affective Disorder and Schizophrenia for School-Age Children - Present and Lifetime Version (K-SADS-PL): initial reliability and validity data. J Am Acad Child Adolesc Psychiatry 1997; 36: 980-8.

16 Saigh PA, Yasik AE, Oberfield RA, Green BL, Halamandaris PV, Rubenstein $H_{\text {, }}$ et al. The Children's PTSD Inventory: development and reliability. J Trauma Stress 2000; 13: 369-80.

17 Alisic E, Jongmans MJ, van Wesel F, Kleber RJ. Building child trauma theory from longitudinal studies: a meta-analysis. Clin Psychol Rev 2011; 31 : 736-47

18 Brosbe MS, Hoefling K, Faust J. Predicting posttraumatic stress following pediatric injury: a systematic review. J Pediatr Psychol 2011; 36: 718-29.

19 Cox CM, Kenardy JA, Hendrikz JK. A meta-analysis of risk factors that predict psychopathology following accidental trauma. J Spec Pediatr Nurs 2008; 13 98-110.

20 Furr JM, Comer JS, Edmunds JM, Kendall PC. Disasters and youth: a meta-analytic examination of posttraumatic stress. J Consult Clin Psychol 2010; 78: 765-80.

21 Kahana SY, Feeny NC, Youngstrom EA, Drotar D. Posttraumatic stress in youth experiencing illnesses and injuries: an exploratory meta-analysis Traumatology 2006; 12: 148-61.

22 Trickey $D$, Siddaway AP, Meiser-Stedman R, Serpell L, Field AP. A meta-analysis of risk factors for post-traumatic stress disorder in children and adolescents. Clin Psychol Rev 2012; 32: 122-38.

23 Wilson DB. Meta-analysis Macros for SAS, SPSS, and Stata 2006. http://mason.gmu.edu/ dwilsonb/ma.html.

24 Lipsey MW, Wilson DB. Practical Meta-analysis. Sage, 2001.

25 Wechsler-Zimring A, Kearney CA. Posttraumatic stress and related symptoms among neglected and physically and sexually maltreated adolescents. J Trauma Stress 2011; 24: 601-4.
26 Hoven CW, Duarte CS, Lucas CP, Wu P, Mandell DJ, Goodwin RD, et al. Psychopathology among New York City public school children 6 months after September 11. Arch Gen Psychiatry 2005; 62: 545-52.

27 Olff M, Langeland W, Draijer N, Gersons BP. Gender differences in posttraumatic stress disorder. Psychol Bull 2007; 133: 183-204.

28 Santiago PN, Ursano RJ, Gray CL, Pynoos RS, Spiegel D, Lewis-Fernandez R, et al. A systematic review of PTSD prevalence and trajectories in DSM-5 defined trauma exposed populations: intentional and non-intentional traumatic events. PLOS One 2013; 8: e59236.

29 Freyd J. Betrayal Trauma. The Logic of Forgetting Childhood Abuse. Harvard University Press, 1996.

30 Janoff-Bulman R. Shattered Assumptions: Towards a New Psychology of Trauma. Free Press, 1992.

31 Kessler RC. Posttraumatic stress disorder: the burden to the individual and to society. J Clin Psychiatry 2000; 5: 4-12.

32 Saigh PA, Mroueh M, Bremner JD. Scholastic impairments among traumatized adolescents. Behav Res Ther 1997; 35: 429-36.

33 Seng JS, Graham-Bermann SA, Clark MK, McCarthy AM, Ronis DL. Posttraumatic stress disorder and physical comorbidity among female children and adolescents: results from service-use data. Pediatrics 2005 116: e767-76.

34 Hankin BL, Abramson LY, Moffitt TE, Silva PA, McGee R, Angell KE. Development of depression from preadolescence to young adulthood: emerging gender differences in a 10-year longitudinal study. J Abnorm Psychol 1998; 107: 128-40.

35 Wittchen HU, Schonfeld S, Thurau C, Trautmann S, Galle M, Mark K, et al Prevalence, incidence and determinants of PTSD and other mental disorders: design and methods of the PID-PTSD+3 study. Int J Methods Psychiatr Res 2012; 21: 98-116.

36 Rosner R, Arnold J, Groh EM, Hagl M. Predicting PTSD from the Child Behavior Checklist: data from a field study with children and adolescents in foster care. Child Youth Serv Rev 2012; 34: 1689-94.

37 Lemos-Miller A, Kearney CA. Depression and ethnicity as intermediary variables among dissociation, trauma-related cognitions, and PTSD symptomatology in youths. J Nerv Ment Dis 2006; 194: 584-90.

38 Suliman S, Kaminer D, Seedat S, Stein D. Assessing post-traumatic stress disorder in South African adolescents: using the child and adolescent trauma survey (CATS) as a screening tool. Ann Gen Psychiatry 2005; 4: 2.

39 Thompson SG, Higgins JP. How should meta-regression analyses be undertaken and interpreted? Stat Med 2002; 21: 1559-73.

40 Finkelhor D, Ormrod RK, Turner HA. Lifetime assessment of poly-victimization in a national sample of children and youth. Child Abuse Negl 2009; 33: 403-11.

41 Merikangas KR, Swanson SA. Comorbidity in anxiety disorders. Curr Top Behav Neurosci 2010; 2: 37-59.

42 Elhai JD, Miller ME, Ford JD, Biehn TL, Palmieri PA, Frueh BC. Posttraumatic stress disorder in DSM-5: estimates of prevalence and symptom structure in a nonclinical sample of college students. J Anxiety Disord 2012; 26: 58-64.

43 Scheeringa MS. Developmental considerations for diagnosing PTSD and acute stress disorder in preschool and school-age children. Am J Psychiatry 2008; 165: 1237-9. 